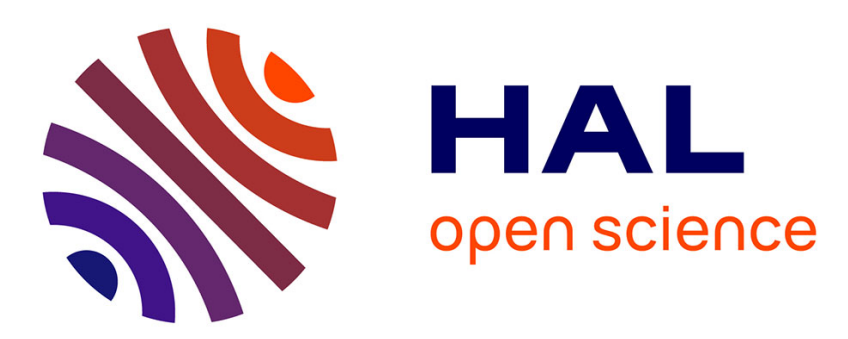

\title{
Tuning the Chemical Communication of Oscillating Microdroplets by Means of Membrane Composition
}

Kristian Torbensen, Sandra Ristori, Federico Rossi, Ali Abou-Hassan

\section{To cite this version:}

Kristian Torbensen, Sandra Ristori, Federico Rossi, Ali Abou-Hassan. Tuning the Chemical Communication of Oscillating Microdroplets by Means of Membrane Composition. Journal of Physical Chemistry C, 2017, 10.1021/acs.jpcc.7b04615 . hal-01534120

\section{HAL Id: hal-01534120 \\ https://hal.sorbonne-universite.fr/hal-01534120}

Submitted on 7 Jun 2017

HAL is a multi-disciplinary open access archive for the deposit and dissemination of scientific research documents, whether they are published or not. The documents may come from teaching and research institutions in France or abroad, or from public or private research centers.
L'archive ouverte pluridisciplinaire HAL, est destinée au dépôt et à la diffusion de documents scientifiques de niveau recherche, publiés ou non, émanant des établissements d'enseignement et de recherche français ou étrangers, des laboratoires publics ou privés. 


\section{Tuning the Chemical Communication of}

\section{Oscillating Microdroplets by Means of Membrane}

\section{Composition}

Kristian Torbensen, ${ }^{a} \dagger$ Sandra Ristori ${ }^{b}$ Federico Rossi,,$^{c}{ }^{*}$ and Ali Abou-Hassan ${ }^{a *}$

a'Sorbonne Universités, UPMC Univ Paris 06, UMR 8234, Laboratoire Physico-chimie des

Electrolytes, Nanosystèmes InterfaciauX (PHENIX), 4 place Jussieu - case 51, 75252 Paris cedex 05 - France.

${ }^{b}$ Department of Chemistry \& CSGI, University of Florence, Via della Lastruccia 3, 50019 Sesto Fiorentino, Firenze, Italy

${ }^{\mathrm{c}}$ Department of Chemistry and Biology, University of Salerno, Via Giovanni Paolo II 132, Fisciano (SA), Italy.

\section{AUTHOR INFORMATION \\ $\dagger$ These authors contributed equally. \\ *Authors to whom correspondence should be addressed.}

Federico Rossi: frossi@unisa.it

Ali Abou-Hassan: ali.abou_hassan@upmc.fr 


\section{Abstract:}

Synchronization of dynamic elements via chemical communication is a widespread phenomenon in nature, and hence in many scientific fields such as in biology, physics and chemistry, where systems capable of giving and receiving informationare commonly found. In these systems coupling and synchronization between elements is achieved by messenger molecules diffusing from one element to others which trigger and spread a chemical reaction. In nature, an important example of chemical communication and synchronicity can be found in cell populations where the plasma membrane governs the trafficking of ions or molecules (among other mechanisms) into and out of the cells, thus dictating their collective dynamic. Herein, in a biomimetic approach, we used a microfluidic system to confine a "chemical information generator", consisting of the far-from-equilibrium Belousov-Zhabotinsky (BZ) reaction in the aqueous core of monodisperse simple emulsion microdroplets. These microdroplets were surrounded by an oil phase containing the phospholipid 1,2-dimyristoylsn-glycero-3-phosphocholine (DMPC), doped with other amphiphilic molecules. Stabilized by the lipids layer contained in the oil phase, the drops could be brought in closest contact to be arranged in a 1D array, using a microfluidic device. The as-formed lipid membrane, at the contact surface, provided a diffusion path between the drops for the chemical species governing the dynamical behavior of the BZ oscillating reaction. We showed, that the coupling mediated by the membranes had mostly an inhibitory character, and that the communication could be controlled by the insertion of sodium tetradecyl sulfate and cholesterol as membrane dopants.

Numerical simulations suggested, that the hydrophobic properties and the lipid packing at the interface were of paramount importance for the trans-membrane crossing of the pertinent chemical species. 


\section{Introduction}

Cooperative and synchronized behavior in networks of biological oscillating systems is a widespread phenomenon in nature. The cooperative and synchronous contraction/expansion in cardiac pathologies related to the heart muscles, in morphogenesis, calcium-signaling dynamics, decentralized bacterial quorum sensing, etc. ${ }^{1-3}$ These synchronization phenomena proceed via diffusive coupling of individual microreactors, e.g. cells and neuron/receptor couples, by mutual exchange of chemical messenger species capable of triggering a chemical reaction or an electrochemical response. Such reactiondiffusion systems have been modeled by chemically coupled microdrops containing the Belousov-Zhabotinsky oscillating reaction. ${ }^{4-12}$ The overall reaction is driven by the oxidation of an organic substrate, e.g. malonic acid, by bromate in acidic solution in the presence of a catalytic specie in the form of an organo-metal complex, such as ferroin (a phenanthrolineiron(II) complex). The oscillatory dynamics however, is governed by the amount of the inhibitory intermediate bromine and the excitatory intermediate bromous acid, present in the microdrops, i.e., the fluctuation of their concentrations governs the oscillatory behaviour of the microdrops. These BZ intermediates might diffuse between individual microdrops, thus affecting the overall oscillatory synchrony of multiple drop arrays. As such, the intermediates serve as messenger molecules between individual drops. For drops separated by an oil gap, the BZ intermediates must diffuse through this gap to reach surrounding drops. Any chemical reaction between the intermediates and species present in the oil phase, will thus diminish the impact on the surrounding drops. ${ }^{7}$ For drops in contact, one or more surfactant layers are formed at the contact region between adjacent drops. ${ }^{13}$ Such layers, if partially permeable to the $\mathrm{BZ}$ intermediates, then open a second communication pathway. ${ }^{14-17}$ By tuning the concentrations of the BZ components within the microdrops, the geometrical configurations of the drops, and the physico-chemical properties of the diffusive pathway, both inhibitory 
and excitatory coupling could be achieved. Another way to control the coupling between microdrops suspended in an oil phase, is by chemical modification of the drop-stabilizing surfactant initially dissolved in the oil phase.

Here, we analyze the coupling patterns obtained in BZ containing microdrops, suspended in a phospholipid-containing oil phase, and brought into contact in a 1D array. To diminish the complexity of the communication pathway between droplets, membranes with small lamellarity are desirable; in this way the permeability of the BZ intermediates is favored, and the global dynamics of the oscillator network can be understood in details. 1,2dimyristoyl-sn-glycero-3-phosphocholine (DMPC) is known to form stable bilayers in water and to self-assemble spontaneously at the water-oil interface. ${ }^{18}$ DMPC was thus used in our experiments as the principal component of the membranes. The exact structure of DMPC at the water-oil interface is difficult to assess since, with respect to the case of an air/water interface, the solubility of phospholipids in organic solvents is an additional parameter which influences the equilibrium conditions. However, at concentrations higher than the critical value of surface coverage, the building-up of a three dimensional structure at the boundary between the organic phase and water has been demonstrated ${ }^{18}$ and it is well accepted that a bilayer is formed by phospholipids at the touching point of two adjacent phospholipidstabilized simple emulsions. ${ }^{14-17,19}$ Recently, ${ }^{20}$ we showed that in DMPC vesicles, the presence of membrane doping molecules having amphiphilic characteristics similar to the DMPC but different packing properties (myristic acid, sodium tetradecyl sulfate and tetradecylamine), induced the transition of the bilayers to a mono-lamellar structure. Moreover, dopants also influenced the oscillatory behavior of the BZ due to the interaction with the different BZ intermediates. ${ }^{20}$ Therefore, in order to work at low lamellarity of the membranes between the touching droplets, we have decided herein to disperse the oscillators in an oil phase containing DMPC doped with sodium tetradecyl sulfate (STS); Cholesterol (CHOL) was also used to 
interact with brominated $\mathrm{BZ}$ intermediates and tune the communication between droplets. We used a microfluidic methodology to build a reproducible, micrometric, homogeneous and space organized 1D arrays of microdroplets encapsulating an oscillatory ferroin catalyzed BZ. 


\section{Experimental}

1,2-Dimyristoyl-sn-glycero-3-phosphocholine (DMPC) was purchased by Lipoids, Inc. Sodium bromate, malonic acid (MA), cholesterol (CHOL), sodium tetradecylsulfate (STS), and sulfuric acid (96\%) were all purchased from Sigma-Aldrich, and used without further purification. Ferroin was synthesized by adding 1.10-phenanthrolin to an aqueous (Milli-Q grade) solution of iron(II) sulfate in the stoichiometric ratio 3:1. Both these chemicals were purchased from Sigma-Aldrich. Chloroform and cyclohexane (both analytical grade) were purchased from Sigma-Aldrich.

To generate the droplets encapsulating the BZ reaction, a homemade microfluidic system was used. It is based on coaxial flow geometry (see Figure 1A) with two separated inner capillaries centered in the middle of an outer capillary. This configuration allows for mixing only in the microfluidic system, thus avoiding problems related to chemical reactions occurring prior to monitoring. The microfluidic device consisted of two fused (using epoxy resin) polyimide coated 150/50 $\mu \mathrm{m}$ (outer diameter (OD)/ inner diameter (ID)) glass capillary tubes (Polymicro) inserted into a cylindrical 1200/485 $\mu \mathrm{m}$ (OD/ID) polytetrafluoroethylene (PTFE) tube (UpChurch Scientific), using a T-junction with ferules (UpChurch Scientific, ref. P-728). Sulfuric acid, malonic acid and ferroin were pumped through one of the fused glass capillary tubes, while sodium bromate was pumped through the other, using syringe pumps (KD Scientific) with a volumetric flow $=10 \mu \mathrm{L} \cdot \mathrm{min}^{-1}$. Thus, no reactions occur prior to mixing of the two aqueous phases in the PTFE tube. The final concentrations of the BZ components in the drops were $0.3 \mathrm{M}, 0.3 \mathrm{M}, 5 \mathrm{mM}$, and $0.12 \mathrm{M}_{\text {for }} \mathrm{H}_{2} \mathrm{SO}_{4}, \mathrm{MA}$, ferroin and sodium bromate, respectively. The suspending oil phase, consisted of a mixture of chloroform/cyclohexane (1:2), DMPC $(0.8 \% \mathrm{w} / \mathrm{w})$ and STS $(0.2 \% \mathrm{w} / \mathrm{w})$ and was injected into the PTFE tube via the T-junction, as sketched in Figure $1 \mathrm{~A}$, with a volumetric flow $=15$ $\mu \mathrm{L} \cdot \mathrm{min}^{-1}$. Once an array of drops (at least 50 drops) were formed (Figure 1B), the PTFE was removed from the T-junction and sealed in both ends with syringes (OD $500 \mu \mathrm{m}$ ) filled with epoxy resin. Recordings ( 1 frame/s) of the oscillating drops were performed with a Zeiss Discovery V8 microscope mounted with a Dasla CCD camera. An induction period of the BZ reaction of approximately $2 \mathrm{~min}$. was sufficient enough to initiate the recordings prior to the first BZ oscillation. 


\section{Results}

A $\mathrm{NaBrO}_{3}$

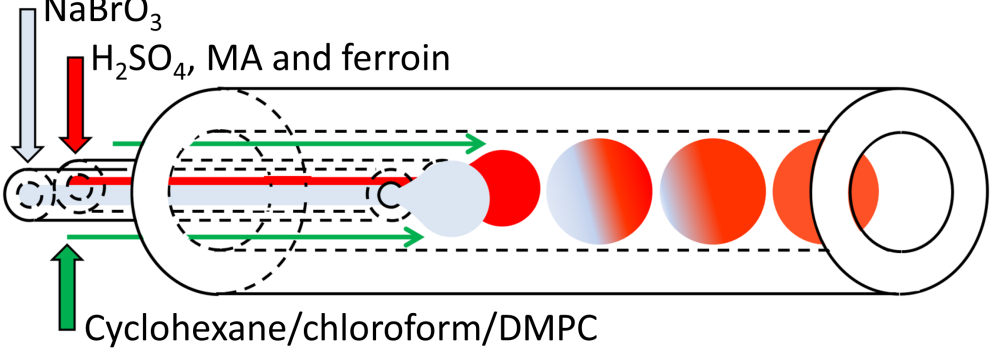

B

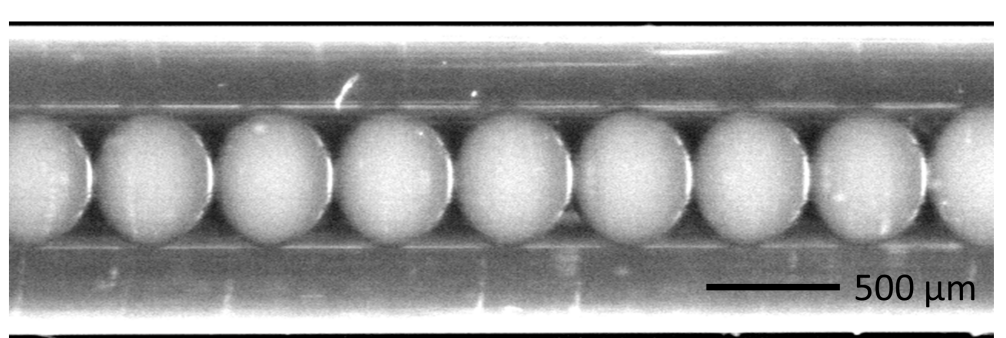

Figure 1. (A) Sketch of the microfluidic device used to generate the droplet arrays, showing the principal of the coaxial flow of the $\mathrm{BZ}$ reactants prior to the drop formation. (B) $1 D$ array of $\mathrm{BZ}$ containing droplets as collected in a PTFE tube for monitoring.

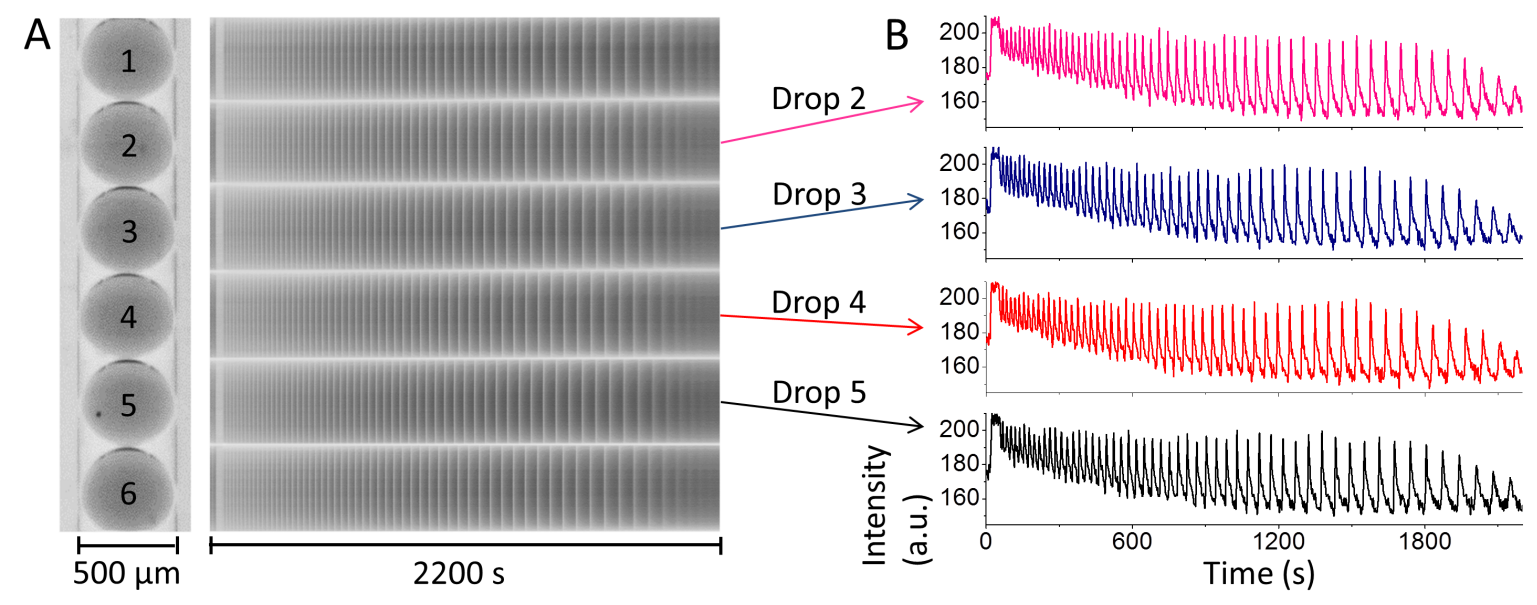

Figure 2. (A) Array of six oscillating droplets in a BZ/DMPC+STS simple emulsion system. Space-Time plots of each droplet were reconstructed from the movie frames (sampling time $1 \mathrm{~s}$ ). (B) Time-series extracted from the space-time plots by converting the pixels in grey scale values. 
Figure 2A shows a simple emulsion array of six oscillating droplets loaded with BZ, and surrounded by a mixture of cyclohexane/chloroform containing 1,2-dimyristoyl-snglycero-3-phosphocholine (DMPC) and sodium tetradecyl-sulphate used as dopant (20\% w/w of the total surfactants). On the right of the array, the space-time (ST) plots display the oscillating dynamics of each droplet. Herein, the vertical bright lines correspond to a firing (oxidized catalyst) of the oscillator, whilst the dark regions represent the recovery period (reduced catalyst) between single oscillations. From the ST plots of four droplets (D2 - D5), the time-series were extracted by converting the pixels along a horizontal line, parallel to the time axis, in grey scale values; the corresponding time-series are reported in Figure 2B. By analyzing the phases and the periods of the selected droplets, it was possible to seek for emerging coherent dynamics due to the coupling between neighboring oscillators. In fact, each oscillator is able to exchange reaction intermediates through the lipid membrane, thus affecting the dynamical evolution of the array. In this setting each oscillator is influenced by messenger molecules released by droplets within close vicinity. Several works $s^{4,7,21-22}$ showed, that the most important intermediates governing the global behavior of a network of diffusively coupled $\mathrm{BZ}$ chemical oscillators are the inhibitors $\left(\mathrm{Br}^{-}\right.$and $\left.\mathrm{Br}_{2}\right)$ and the activators $\left(\mathrm{HBrO}_{2}, \mathrm{BrO}_{2}{ }^{\circ}\right.$, and the organic substrates MA or BrMA). Oscillations periods $(\tau)$ were calculated from the time-series as the time difference between two successive maxima, while the oscillation frequency $(\omega)$, measured in $\mathrm{Hz}$, is calculated as the reciprocal of $\tau(\omega=1 / \tau)$. The oscillators array is thermodynamically closed; therefore, oscillations have a transitory nature that causes a continuous drift in the oscillating parameters. This fact makes it difficult to determine whether the changes in the oscillation dynamics of coupled droplets are the result of random fluctuations, or a consequence of the mutual entrainment. To reduce this uncertainty, we here analyze the oscillating parameters by following different methodological approaches. 
At a first glance, panels in Figure 2 suggest a coherent behavior of the type $a-b-a-b$, by which next neighbor droplets oscillate with nearly identical periods. Figure 3 shows a more thorough analysis of $\tau$, as extrapolated from the time-series of the droplets $2-5$. These droplets were chosen in the array, since they all have the same boundary conditions (i.e., each droplet is in contact with its two neighbors, and the array extends to both sides with approximately 20 droplets). The same analysis extended to drops 1 and 6 confirmed a coherent $a-b-a-b$ behavior (not shown).
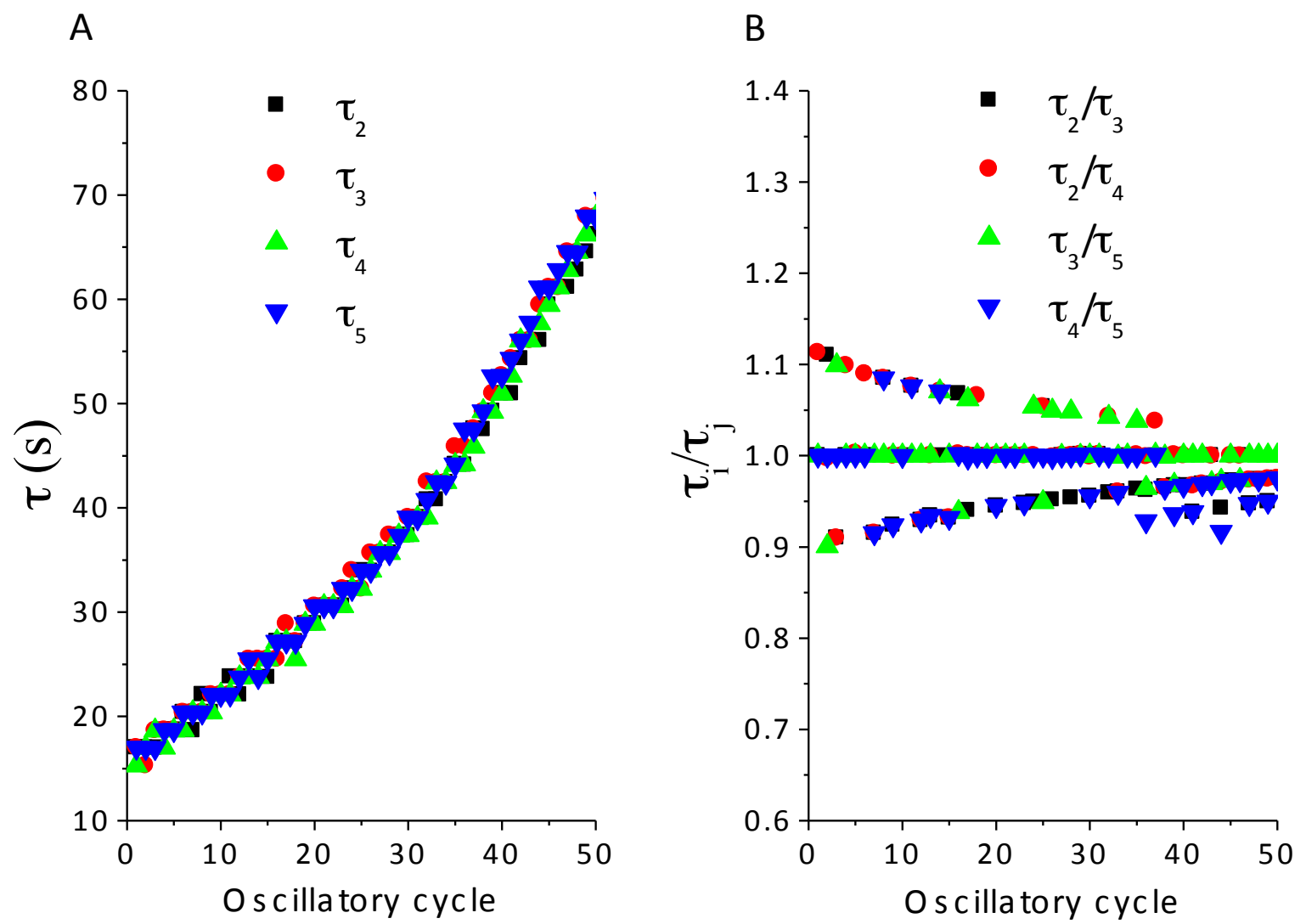

Figure 3. (A) Oscillation periods, derived from the ST-plots of the droplets $2-5$ in Figure 2, plotted vs. the oscillatory cycle number. (B) Ratio of oscillation periods between the droplets couples.

In Figure 3A, the oscillation periods of each droplet are plotted as a function of the oscillatory cycles. First oscillations periods are nearly identical $(\sim 18 \mathrm{~s})$, and all the droplets flash at the same time, as expected for identical oscillators with equal initial concentrations of 
reactants. As the reaction develops, reactants are being consumed, and the kinetics parameters change over time; this is reflected in slower dynamics, which brings the oscillation periods up to $\sim 70 \mathrm{~s}$ for all the droplets.

After the initial phase and period synchronization, each droplet experiences small changes in the oscillation time, as highlighted by the period ratio vs. time plot shown in Fig. 2B, where $\tau_{\mathrm{i}} / \tau_{\mathrm{j}}$ occasionally deviates from unit. The consequence of this period adjustment is a phase shift between droplets, which can be better understood by studying the phase behavior over time. We calculated the instantaneous unwrapped phase of the four droplets by means of equation (1.1), as reported in Figure 4A

$$
\phi_{i}=2 \pi \frac{t-t_{k}}{t_{k+1}-t_{k}}+2 k \pi \quad t_{k}<t<t_{k+1}
$$

where $t_{k}$ is the time of the $k$-th peak of the oscillatory time series of the $i$-th oscillator. As in the case of $\tau$, the unwrapped phases are identical in the beginning of the experiment, but diverge slightly over time. In particular, the trend of the phase difference $\left(\Delta \phi_{i, j}\right)$, as depicted in Figure $4 \mathrm{~B}$ and $\mathrm{C}$, suggests that alternate droplets $(2,4$ and 3,5$)$ tend to oscillate in-phase, whilst adjacent droplets progressively tend to oscillate with a phase difference of $\pi$, i.e., in an anti-phase oscillatory behavior. In general, a diagonal trend of $\Delta \phi_{i, j}$ corresponds to a phase difference which is not constant over time, while horizontal trends indicate that both oscillators have the same period and oscillate with a constant phase difference. This latter situation represents a "phase lock" state (i.e., a coherent behavior of the elements constituting the couple). 

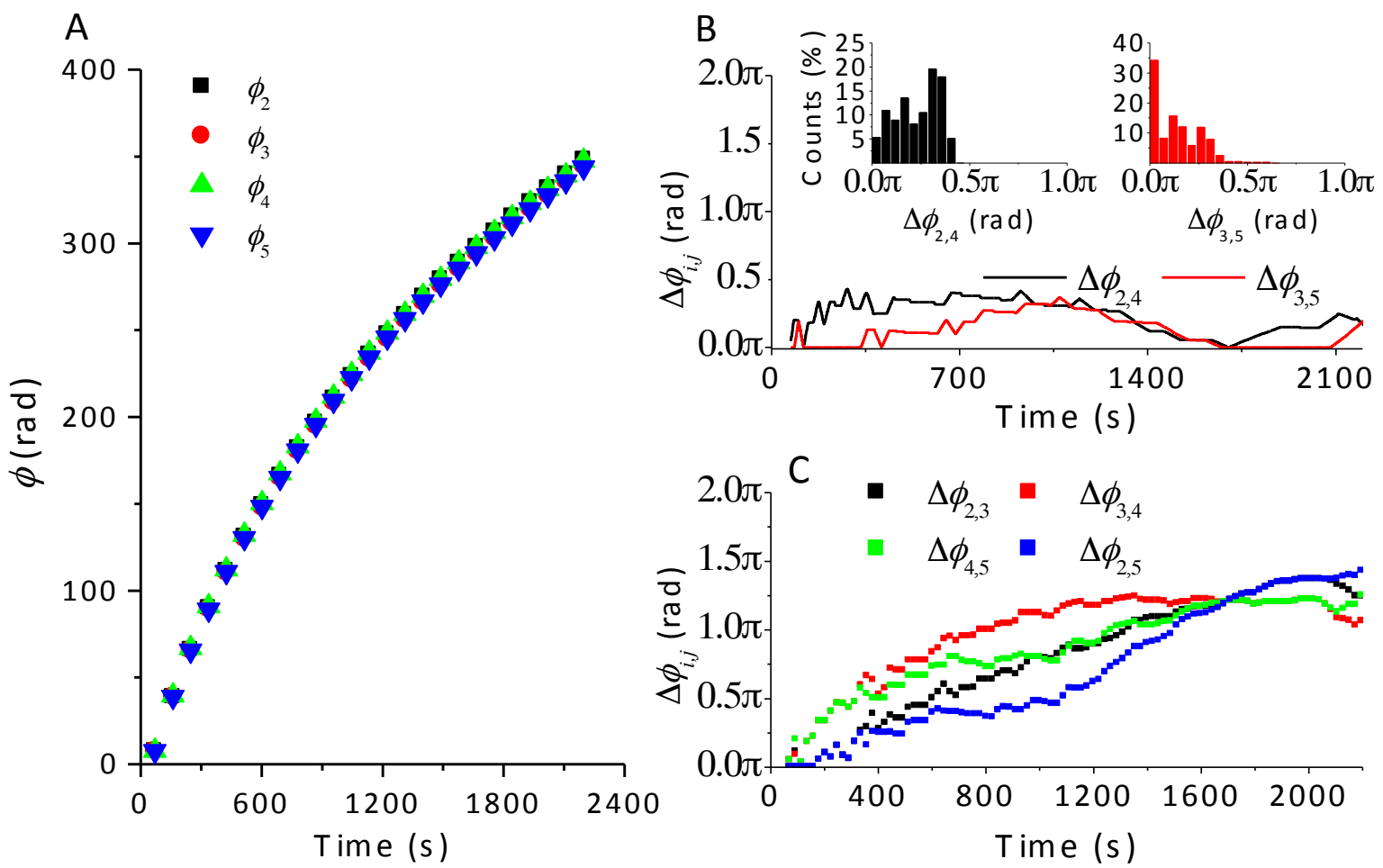

Figure 4. (A) Unwrapped phase, as calculated by eq. (1.1), for the droplets 2 - 5 in Figure 2. (B) Phase difference of the alternate droplets 2,4 and 3,5, as a function of time. The inset in $B$ shows the count distribution for various intervals of phase differences. (C) Phase differences of adjacent droplet couples vs. time, displaying the progressive phase shift to anti-phase oscillations.

The diagonal intervals in Figure $4 \mathrm{C}$ show that, during the course of the reaction, the phase difference between adjacent droplets undergoes small adjustments in response to the variation of the oscillation period until a plateau value around $\pi$ is attained after $\sim 1000 \mathrm{~s}$. On the contrary, Figure 4B shows that the phase difference between alternate droplets is embedded in a defined range, $0-0.4 \pi$. The frequency distribution of $\Delta \phi_{i, j}$ (insets of Fig. $4 \mathrm{~B}$ ), shows that the phase difference is distributed around an average value of $0.2 \pi$ for both the couples, meaning that the alternate droplets tend to oscillate in-phase. The global behavior of the array is then of the type $a-b-a-b$, with $a$ and $b$ oscillating in anti-phase; this dynamics is typical of 
an inhibitory coupling, as previously characterized in oil-in-water emulsions by Epstein and coworkers. $^{4-5,7}$

To confirm the prominent role of brominated species $\left(\mathrm{Br}_{2}, \mathrm{Br}^{-}\right)$as inhibitory messengers among different microdroplets, we modified the membrane composition in order to modulate the communication pathway, and seek a difference in the global behavior of the array. Recently, ${ }^{20}$ we showed that the interaction of $\mathrm{Br}_{2}$ with the double bonds of cholesterol caused some differences in the oscillation period and frequency of the BZ reaction. We thus expect cholesterol-doped DMPC membranes to act as a barrier for $\mathrm{Br}_{2}$, thus preventing, or at least mitigating, inhibitory coupling.
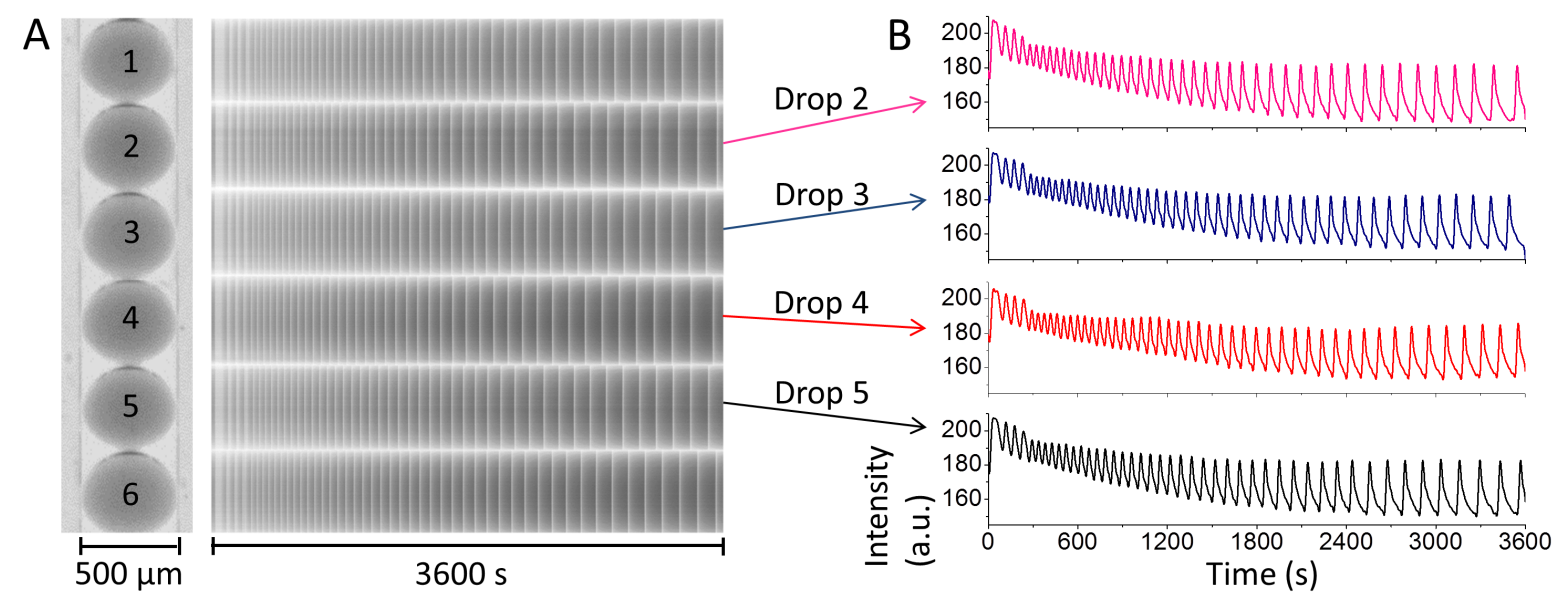

Figure 5. (A) Array of six oscillating droplets in a BZ/DMPC+CHOL simple emulsion system. Space-time plots of each droplet were reconstructed from the movie frames recorded (sampling time $1 \mathrm{~s}$ ). (B) Timeseries extracted from the space-time plots by converting the pixels in grey scale values.

Figure 5A shows a simple-emulsion (cyclohexane/chloroform-BZ) array of six oscillating droplets, coated by DMPC phospholipid monolayer doped with cholesterol $(20 \% \mathrm{w} / \mathrm{w})$. Similarly to Figure 2, the time-series of four droplets (D2 - D5) were extracted from the ST plots and converted in grey scale values (Figure 5B). The same analysis as for the 
DMPC+STS system was applied here to seek for differences in the global behavior induced by the membrane composition.

The period analysis of the CHOL-DMPC system reveals a less defined behavior with respect to the DMPC+STS system. In Figure 6A, the oscillation periods of each droplet are plotted as a function of the oscillatory cycles. During the first oscillations, periods are distributed quite evenly around a mean value of $50 \mathrm{~s}$, without any evidence of a coherent behavior. After this initial stage, droplets begin to oscillate with similar periods but without an apparently ordered trend. This is confirmed also by Figure 6B, where the ratio among the periods of droplet pairs is reported against the oscillatory cycles, showing values of $\tau_{\mathrm{i}} / \tau_{\mathrm{j}}$ that span between 0.8 and 1.2. Both adjacent and alternate droplets seem to randomly change their period in time, thus preventing any type of synchronization.
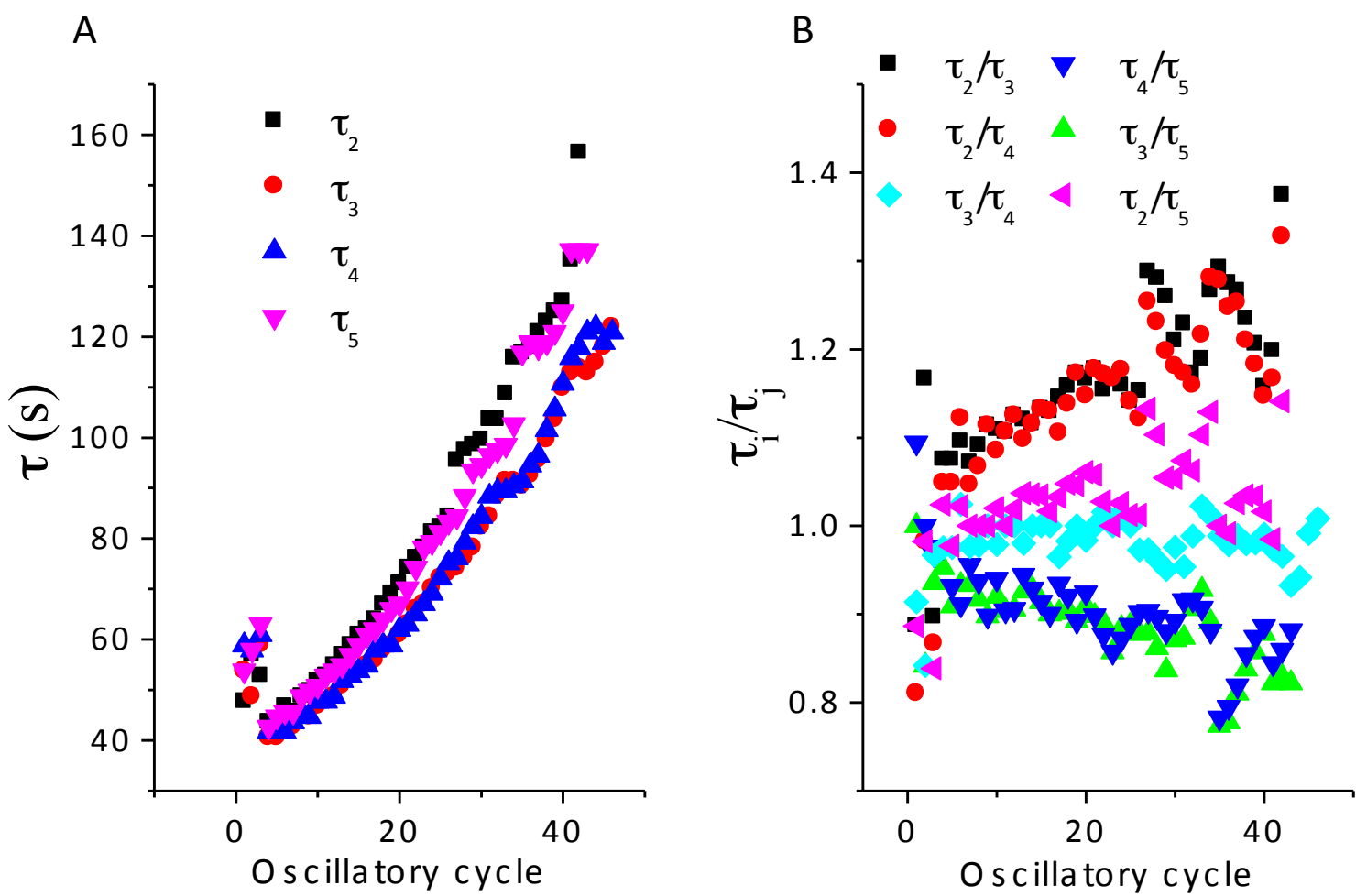

Figure 6. (A) Oscillation periods, derived from the ST-plots of the droplets $2-5$ in Figure 6, plotted vs. the oscillatory cycle number. (B) Ratio of oscillation periods between droplets couples.

The phase analysis confirms this trend, as reported in Figure 7. The phases of the droplets diverge in time (Fig. 7A), with a significant phase difference between two groups. A weak 
phase-coupling between the central drops $(3,4)$ is described by Figure $7 \mathrm{~B}$; here $\Delta \phi_{i, j}$ is distributed around $0.5 \pi$ and $0.8 \pi$, with a period of uncorrelated oscillations between $\sim 1500 \mathrm{~s}$ and $\sim 2200$ s. However, the oscillation dynamics of the other permutated droplet couples are generally uncorrelated, as showed in Figure 7C.
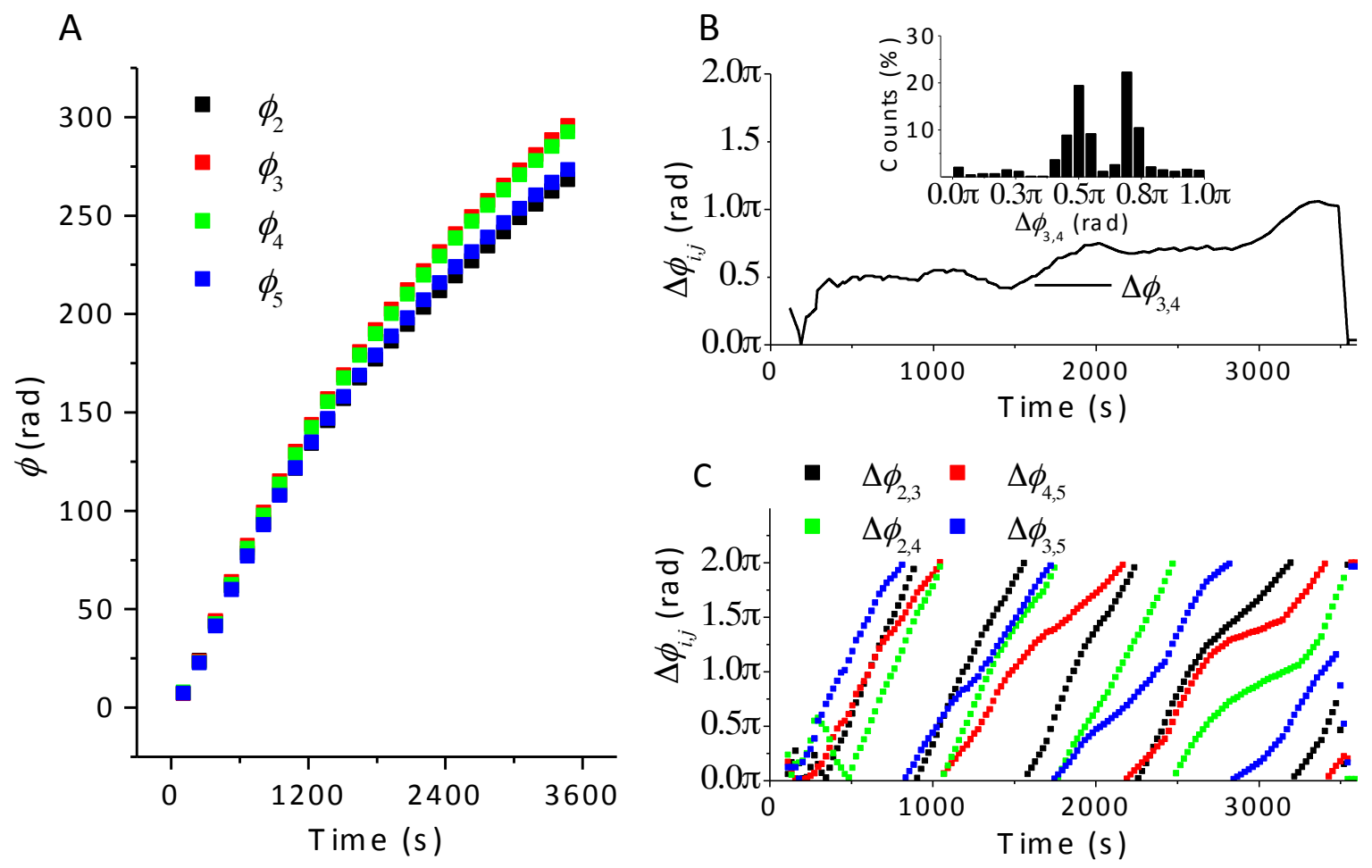

Figure 7. (A) Unwrapped phase, as calculated by eq. (1.1), for the droplets 2 - 5 of Figure 6. (B) Phase difference of the droplet couple 3,4 as a function of time. The inset in (B) shows the count distribution for various intervals of phase differences. (C) Phase differences of the droplet couples $2,3,2,4,4,5$ and 3,5 vs. time, displaying an uncorrelated coupling for these adjacent and alternate droplets.

Despite the weak coupling of the central droplets, the insertion of cholesterol in the DMPC membranes seems to stop the coupling among the oscillators, thus confirming that an inhibitory type of communication takes place across the lipid barriers.

\section{Discussion}


Recently, we investigated several aspects connected with the nature of the messenger molecules transducing chemical signals in a network of oscillating liposomes and we demonstrated, by means of electrochemical techniques, that nonpolar brominated or oxybrominated species can be responsible for signal transduction across DMPC membranes. ${ }^{21,23}$ In a previous work, ${ }^{16}$ we studied the communication among droplets in a double emulsion system (water/oil/water) at high concentration of bromate and sulfuric acid. In this configuration, the production of the autocatalytic species $\mathrm{HBrO}_{2}$ was favored, and the resulting activatory type of coupling led the system to synchronous in-phase oscillating dynamics.

In this work, the comparison between the BZ/DMPC+STS and the BZ/DMPC+CHOL systems indicated a prominent role of an inhibitory coupling in the communication pathways between droplets in the liposome array. With respect to the role of cholesterol, we demonstrated ${ }^{20}$ how the double bonds present in its structure could be saturated by $\mathrm{Br}_{2}$, thus altering the oscillation period of the BZ reaction. In the specific case of the droplet arrays, cholesterol directly influences the communication pathways between droplets by mitigating the passage of $\mathrm{Br}_{2}$ from one droplet to another through the phospholipids membranes. In the case of DMPC+STS membranes, small nonpolar species, both with activatory $\left(\mathrm{BrO}_{2}{ }^{\bullet}, \mathrm{HBrO}_{2}\right.$, etc.) and inhibitory $\left(\mathrm{Br}_{2}\right)$ properties, can cross the membranes. It is unlikely that larger polar molecules $\left(\mathrm{CH}_{2}(\mathrm{COOH})_{2}, \mathrm{CHBr}(\mathrm{COOH})_{2}\right.$, etc.) or the catalyst can cross the phospholipid membranes. ${ }^{24}$ Indeed, ferroin is not only bulkier than carboxylate molecules present in this system, but it also lacks any amphiphilic character, which could facilitate its insertion in the phospholipid bilayers. Finally, the crossing of ionic species with negative charge $\left(\mathrm{Br}^{-}, \mathrm{BrO}_{3}^{-}\right.$, etc.), is strongly hindered, due to electrostatic repulsion with the STS polar heads. Therefore, we focused our attention to the exchange of two species, $\mathrm{HBrO}_{2}$ and $\mathrm{Br}_{2}$, responsible for activatory and inhibitory coupling, respectively., 7, 16, 21-22 


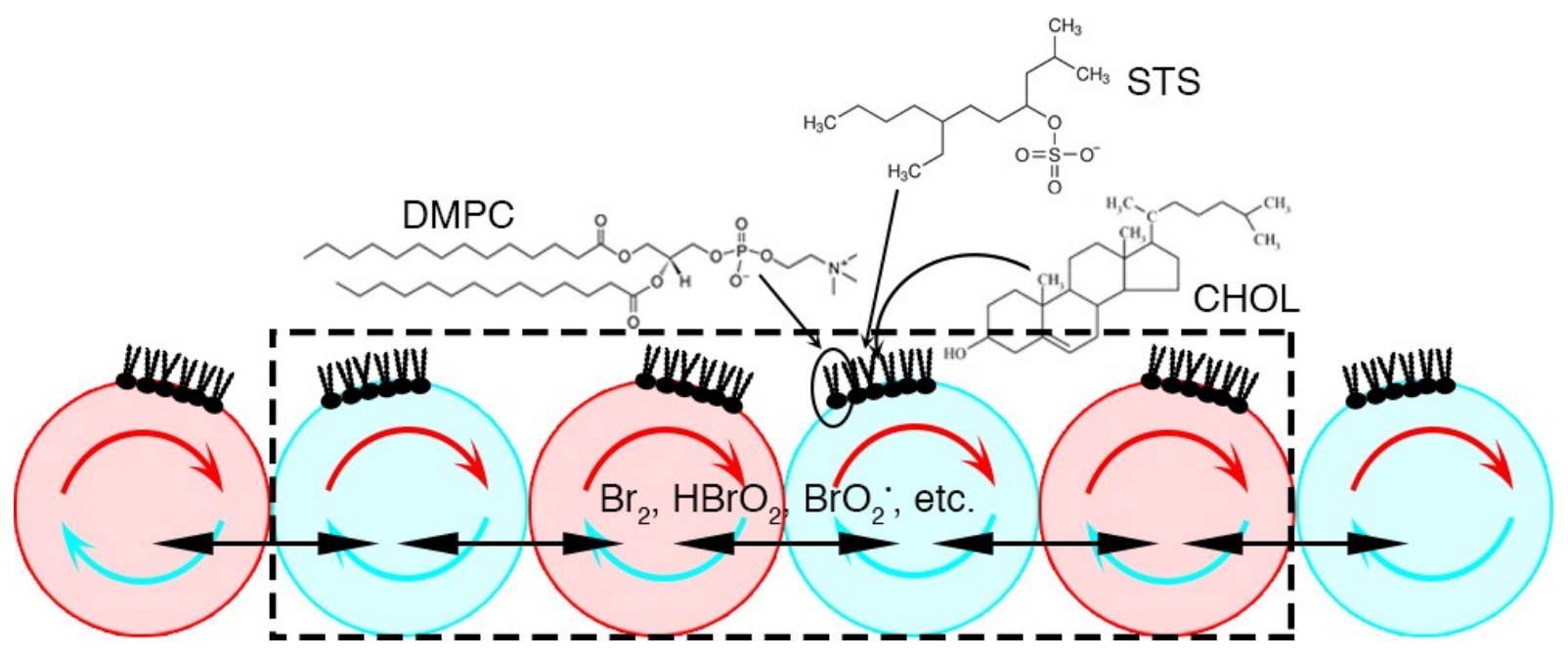

Figure 8. Model of the BZ oscillator array. DMPC was used as a major structural unit for the monoand bilayer membranes, the latter present at all the droplet interfaces, alternatively intercalated with CHOL and STS molecules. The segmented square indicates the monitored droplets in the simulations.

Numerical simulations can be useful to understand the influence of the membrane composition on the global dynamics of the droplets array. The system can be modeled as sketched in Figure 8: Six droplets, each of them containing the BZ reaction, are free to exchange $\mathrm{HBrO}_{2}$ and $\mathrm{Br}_{2}$ through a simple equilibrium reaction following mass action kinetics

$$
\begin{aligned}
& \mathrm{Br}_{2}\left(d_{i}\right) \underset{k_{-c}^{1}}{\stackrel{k_{c}^{1}}{\rightleftarrows}} \mathrm{Br}_{2}\left(d_{j}\right) \\
& \mathrm{HBrO}_{2}\left(d_{i}\right) \underset{k_{-c}^{2}}{\stackrel{k_{c}^{2}}{\rightleftarrows}} \mathrm{HBrO}_{2}\left(d_{j}\right)
\end{aligned}
$$

where $\mathrm{d}_{\mathrm{i}}$ and $\mathrm{d}_{\mathrm{j}}$ represent adjacent droplets, and $k_{c}^{i}=k_{-c}^{i}\left(\mathrm{~s}^{-1}\right)$ are the transfer kinetic constants related with the permeability of the i-th species, $P_{m}^{i}(\mathrm{~cm} / \mathrm{s})$, towards the phospholipid membranes by the relation $k_{c}^{i}=P_{m}^{i} A_{c} / V_{d}$, where $V_{d}$ is the droplet volume $(6.5$ $\left.\times 10^{-5} \mathrm{~cm}^{3}\right)$ and $A_{c}$ is the contact surface area between two droplets $\left(1.37 \times 10^{-4} \mathrm{~cm}^{2}\right)$. The values for $V_{d}$ and $A_{c}$ were determined from our experiments, using the diameter of the droplets $(\sim 500 \mu \mathrm{m})$ and the diameter of the contact area, assumed to be circular $(\sim 130 \mu \mathrm{m})$, 
respectively. The value for $P_{m}^{1}$ was measured by electrochemical techniques for a Langmuir monolayer of different phosphatidylethanolamines, and was found to be $0.07 \mathrm{~cm} / \mathrm{s}$ at a low surface pressure. ${ }^{25}$ The value for $P_{m}^{2}$ was chosen as $1 \times 10^{-4} \mathrm{~cm} / \mathrm{s},{ }^{16,21,26-27}$ so that $k_{c}^{1}=0.15 \mathrm{~s}^{-1}$ and $k_{c}^{2}=2 \times 10^{-4} \mathrm{~s}^{-1}$. Only the four droplets having the same boundary conditions (segmented square in Figure 8) were monitored during the simulations. The BZ system inside each droplet was modeled according to the following reaction scheme $e^{28-30}$ with relative kinetic constants reported in Table 1.

$$
\begin{aligned}
& \mathrm{HOBr}+\mathrm{Br}^{-}+\mathrm{H}^{+} \rightleftarrows \mathrm{Br}_{2}+\mathrm{H}_{2} \mathrm{O} \\
& \mathrm{Br}^{-}+\mathrm{HBrO}_{2}+\mathrm{H}^{+} \rightarrow 2 \mathrm{HOBr} \\
& 2 \mathrm{HBrO}_{2} \rightarrow \mathrm{BrO}_{3}^{-}+\mathrm{HOBr}+\mathrm{H}^{+} \\
& \mathrm{Br}^{-}+\mathrm{BrO}_{3}^{-}+2 \mathrm{H}^{+} \rightleftarrows \mathrm{HOBr}+\mathrm{HBrO}_{2} \\
& \mathrm{BrO}_{3}^{-}+\mathrm{HBrO}_{2}+\mathrm{H}^{+} \rightleftarrows \mathrm{Br}_{2} \mathrm{O}_{4}+\mathrm{H}_{2} \mathrm{O} \\
& \mathrm{Br}_{2} \mathrm{O}_{4} \rightleftarrows 2 \mathrm{BrO}^{\circ} \\
& \mathrm{Fe}(\text { phen })_{3}^{2+}+\mathrm{BrO}_{3}^{-}+2 \mathrm{H}^{+} \rightarrow \mathrm{Fe}(\text { phen })_{3}^{3+}+\mathrm{BrO}_{2}^{\cdot}+\mathrm{H}_{2} \mathrm{O} \\
& \mathrm{Fe}(\text { phen })_{3}^{2+}+\mathrm{BrO}_{2}^{\bullet}+\mathrm{H}^{+} \rightarrow \mathrm{Fe}(\text { phen })_{3}^{3+}+\mathrm{HBrO}_{2} \\
& \mathrm{Fe}(\text { phen })_{3}^{3+}+\mathrm{BrCH}(\mathrm{COOH})_{2} \rightleftarrows \mathrm{Fe}(\text { phen })_{3}^{2+}+{ }^{\circ} \mathrm{CBr}(\mathrm{COOH})_{2}+\mathrm{H}^{+} \\
& \mathrm{BrCH}(\mathrm{COOH})_{2} \rightleftarrows(\mathrm{HOOC}) \mathrm{CBr}=\mathrm{C}(\mathrm{OH})_{2} \\
& (\mathrm{HOOC}) \mathrm{CBr}=\mathrm{C}(\mathrm{OH})_{2}+\mathrm{Br}_{2} \rightarrow \mathrm{Br}_{2} \mathrm{C}(\mathrm{COOH})_{2}+\mathrm{Br}^{-}+\mathrm{H}^{+} \\
& (\mathrm{HOOC}) \mathrm{CBr}=\mathrm{C}(\mathrm{OH})_{2}+\mathrm{HOBr} \rightarrow \mathrm{Br}_{2} \mathrm{C}(\mathrm{COOH})_{2}+\mathrm{H}_{2} \mathrm{O}
\end{aligned}
$$




$$
\begin{aligned}
& 2^{\circ} \mathrm{CBr}(\mathrm{COOH})_{2}+\mathrm{H}_{2} \mathrm{O} \rightarrow \mathrm{BrCOH}(\mathrm{COOH})_{2}+\mathrm{BrCH}(\mathrm{COOH})_{2} \\
& \mathrm{BrCOH}(\mathrm{COOH})_{2} \rightarrow \mathrm{Br}^{-}+\mathrm{CO}(\mathrm{COOH})_{2}+\mathrm{H}^{+}
\end{aligned}
$$

When cholesterol was intercalated in the DMPC membranes, a fast bromination reaction was added to the scheme, similarly to the bulk systems we investigated in our previous work ${ }^{20}$

$$
\mathrm{Br}_{2}+\mathrm{Chol} \stackrel{\mathrm{K}}{\longrightarrow} \mathrm{Br}_{2}-\mathrm{Chol}
$$

with a kinetic rate constant $\mathrm{K}=340 \mathrm{M}^{-1} \mathrm{~s}^{-1}$.

Numerical simulations were performed by integrating the reactions (1.2), (1.3) and (R1) (R15) by means of the CO.PA.SI. software. ${ }^{31}$ All data used in simulations reflected the real experimental parameters, and the different initial conditions of the droplets were reproduced by introducing a small delta in the concentration of the reactants $( \pm 0.1 \%)$.

Table 1. Forward and backward reaction rates for the BZ model involving reactions (R1) (R14).

\begin{tabular}{|l|l|l|}
\hline reaction & $\mathrm{k}_{\text {forward }}$ & $\mathrm{k}_{\text {inverse }}$ \\
\hline R1 & $8 \times 10^{9} \mathrm{~mol}^{-2} \mathrm{dm}^{6} \mathrm{~s}^{-1}$ & $80 \mathrm{~s}^{-1}$ \\
\hline R2 & $2.5 \times 10^{6} \mathrm{~mol}^{-2} \mathrm{dm}^{6} \mathrm{~s}^{-1}$ & \\
\hline R3 & $3 \times 10^{3} \mathrm{~mol}^{-1} \mathrm{dm}^{3} \mathrm{~s}^{-1}$ & \\
\hline R4 & $10 \mathrm{~mol}^{-3} \mathrm{dm}^{9} \mathrm{~s}^{-1}$ & $3.2 \mathrm{~mol}^{-1} \mathrm{dm}^{3} \mathrm{~s}^{-1}$ \\
\hline R5 & $48 \mathrm{~mol}^{-2} \mathrm{dm}^{6} \mathrm{~s}^{-1}$ & $3.2 \times 10^{3} \mathrm{~s}^{-1}$ \\
\hline R6 & $7.5 \times 10^{4} \mathrm{~s}^{-1}$ & $1.4 \times 10^{9} \mathrm{~mol}^{-1} \mathrm{dm}^{3} \mathrm{~s}^{-1}$ \\
\hline R7 & $0.38 \mathrm{~mol}^{-3} \mathrm{dm}^{9} \mathrm{~s}^{-1}$ & \\
\hline R8 & $1 \times 10^{9} \mathrm{~mol}^{-2} \mathrm{dm}^{6} \mathrm{~s}^{-1}$ & \\
\hline
\end{tabular}




\begin{tabular}{|l|l|l|}
\hline $\mathrm{R} 9$ & $100 \mathrm{~mol}^{-1} \mathrm{dm}^{3} \mathrm{~s}^{-1}$ & $6 \times 10^{8} \mathrm{M}^{-2} \mathrm{~s}^{-1}$ \\
\hline $\mathrm{R} 10$ & $0.012 \mathrm{~s}^{-1}$ & $800 \mathrm{~s}^{-1}$ \\
\hline $\mathrm{R} 11$ & $3.5 \times 10^{6} \mathrm{~mol}^{-1} \mathrm{dm}^{3} \mathrm{~s}^{-1}$ & \\
\hline $\mathrm{R} 12$ & $6.6 \times 10^{4} \mathrm{~mol}^{-1} \mathrm{dm}^{3} \mathrm{~s}^{-1}$ & \\
\hline $\mathrm{R} 13$ & $1 \times 10^{8} \mathrm{~mol}^{-1} \mathrm{dm}^{3} \mathrm{~s}^{-1}$ & \\
\hline R14 & $1.5 \mathrm{~s}^{-1}$ & \\
\hline
\end{tabular}
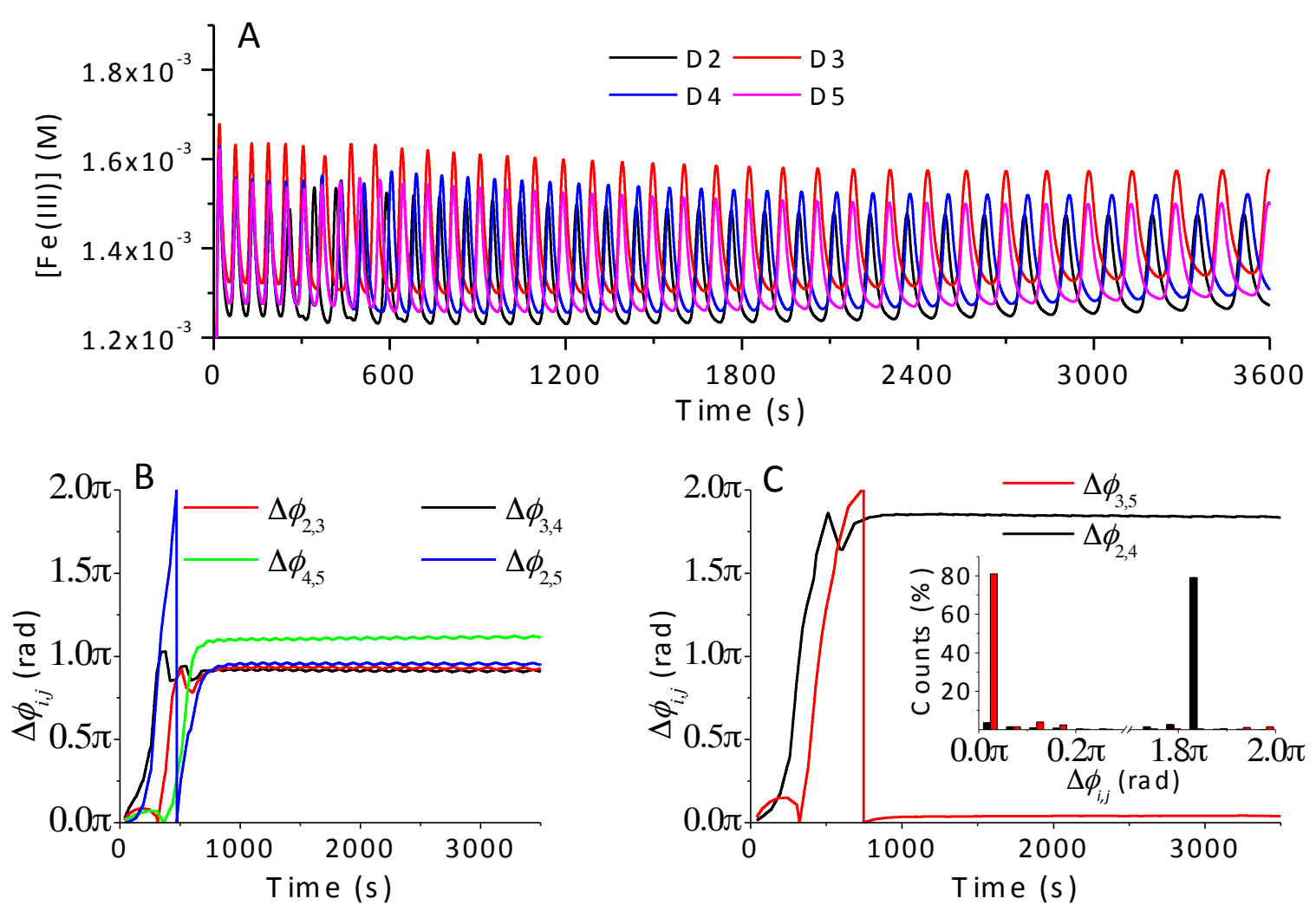

Figure 9. (A) Simulated time-series for the BZ/DMPC+STS system showing an $a-b-a-b$ configuration; around $t=600 \mathrm{~s}$, alternate droplets start to oscillate with the same period and phase. (B) Phase difference for the adjacent droplets oscillating in anti-phase in the DMPC+STS system. (C) Phase difference for the synchronized droplets in the DMPC+STS system.

Figure 9 reports the simulations for the system DMPC+STS, where reaction (R15) was not taken into account, and the concentration of cholesterol in the membranes was set to 0 . Panel 
A shows how, after a few oscillatory cycles between 0 and $600 \mathrm{~s}$, a clear $a-b-a-b$ configuration begins to take place, where alternate droplets start to oscillate with the same period and phase. Panel B reports the phase difference between adjacent droplets that locks on a value close to $\pi$, i.e., they are oscillating in anti-phase. Finally, panel $\mathrm{C}$ depicts the phase difference behavior of the synchronized droplets; the couple D2 - D4 locks on a $\Delta \phi_{2,4}=1.8 \pi(-0.2 \pi)$ while the couple D3 - D5 locks on a $\Delta \phi_{3,5}=0.02 \pi$, as highlighted in the inset of Figure 9C.
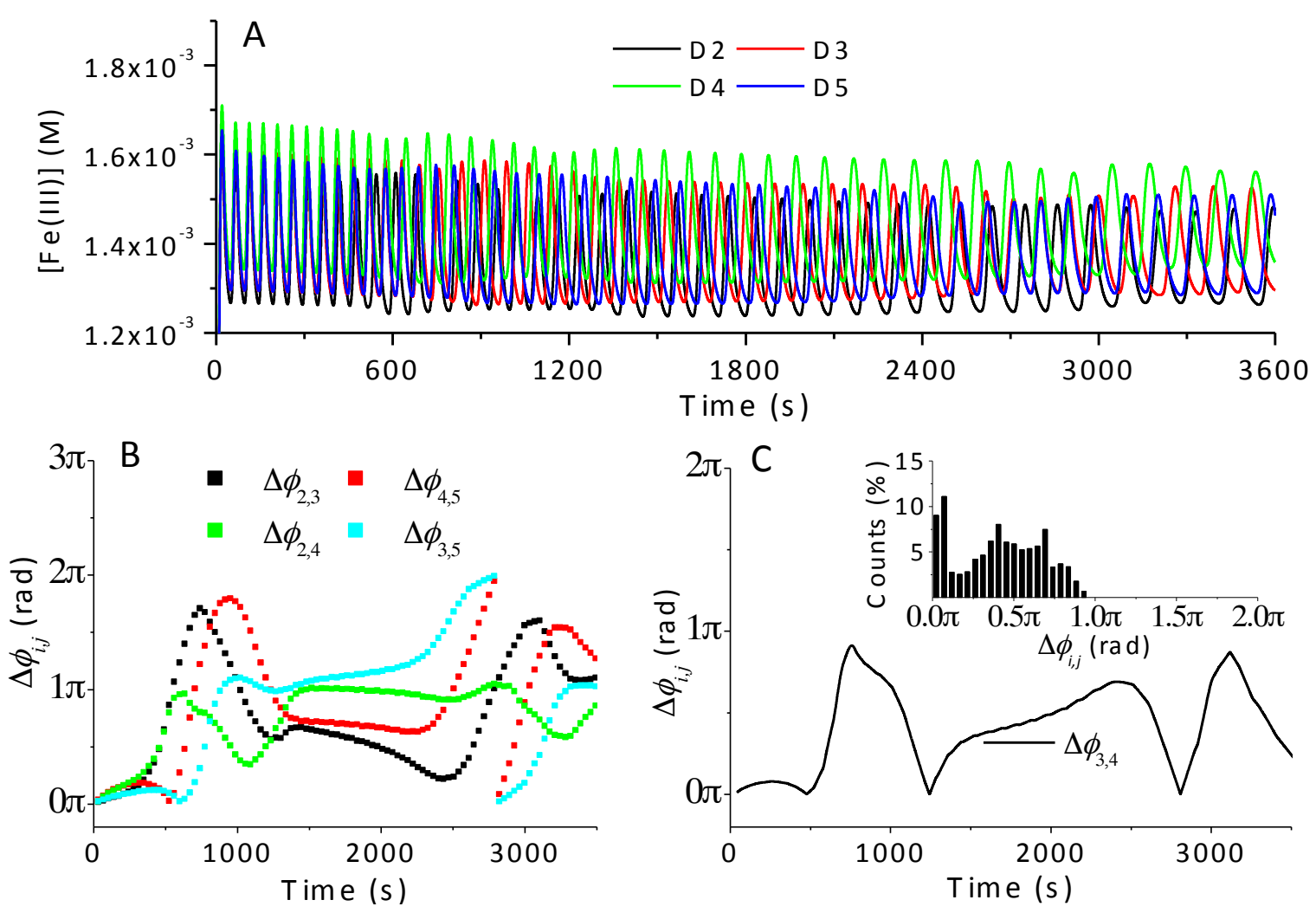

Figure 10. (A) Simulated time-series for the BZ/DMPC+CHOL system, showing a mainly random behaviour of the droplet array; (B) phase difference for adjacent and alternate droplets showing uncorrelated phase behaviour over time. (C) Phase difference for the weakly coupled droplets $(3,4)$ in the DMPC+CHOL system.

When the cholesterol is intercalated into the membranes, the model takes into account the reaction $(\mathrm{R} 15)$ with a concentration of cholesterol $[\mathrm{CHOL}]=6 \times 10^{-3} \mathrm{M}$. The time-series 


\section{Conclusion:}

In this paper, we investigated the influence of the membrane composition on the communication pathways in arrays of touching oscillating microdroplets surrounded by an oil phase containing phospholipids, with two different dopants. The arrays of micro-droplets were fabricated by encapsulating an oscillatory ferroin catalyzed BZ mixture into microdroplets by means of microfluidics. With respect to previous works, here the array configuration allowed for more controlled experimental conditions, and for a longer lifespan of the droplets. Moreover, the presence of STS ensured a low lamellarity of the membranes thus favoring easier communication among the oscillators. For these experimental conditions, the communication between adjacent droplets mainly exhibits an inhibitory character, governed by the prominent role of $\mathrm{Br}_{2}$. Molecular bromine has in fact a higher permeability towards phospholipid membranes with respect to the activator $\mathrm{HBrO}_{2}$, resulting in an out-ofphase oscillatory regime between adjacent droplets and in an in-phase regime between alternating droplets ( $a-b-a-b$ configuration). With cholesterol intercalated in the membrane structure, the global dynamics resulted in a weakly coupled array, with adjacent droplets oscillating almost with the same periods, but with an uncorrelated phase with respect to the pure DMPC+STS case. The primary role of cholesterol was to inhibit the $\mathrm{Br}_{2}$ molecules to pass from one droplet to another, thus allowing for a weak activatory coupling resulting in a slightly synchronized behavior of the central couple of droplets 3,4. 
In conclusion, our experiments showed that by manipulating the droplet membranes, we can tune the communication properties of the oscillator network. In a multi-scale approach more experiments are planned to extend our findings from the simple emulsions system to double emulsions systems (water/oil/water), and finally to a real liposome (water-in-water) network.

\section{ACKNOWLEDGMENT}

K.T. and A.A-H. thank the doctoral school ED388 "Chimie-Physique et Chimie Analytique de Paris Centre" for funding. F.R. was supported by the grants ORSA158121 and ORSA149477 funded by the University of Salerno (FARB ex $60 \%$ ). F.R. and A.A-H. acknowledge the support through the COST Action CM1304 (Emergence and Evolution of Complex Chemical Systems).

\section{Reference:}

1. Strogatz, S. H., Sync: How Order Emerges from Chaos in the Universe, Nature, and Daily Life; Hachette Books, 2004.

2. Kiss, I. Z.; Hudson, J. L. Chemical Complexity: Spontaneous and Engineered Structures. AlChE J 2003, 49, 2234-2241.

3. Perkel, J. M. Membrane Messengers: Extracellular Vesicles. Science 2016, 352, 1349-1351.

4. Delgado, J.; Li, N.; Leda, M.; Gonzalez-Ochoa, H. O.; Fraden, S.; Epstein, I. R. Coupled Oscillations in a 1d Emulsion of Belousov-Zhabotinsky Droplets. Soft Matter. 2011, 7, 3155-3167.

5. Toiya, M.; González-Ochoa, H. O.; Vanag, V. K.; Fraden, S.; Epstein, I. R. Synchronization of Chemical Micro-Oscillators. J. Phys. Chem. Lett. 2010, 1, 1241-1246.

6. Taylor, A. F.; Tinsley, M. R.; Wang, F.; Huang, Z.; Showalter, K. Dynamical Quorum Sensing and Synchronization in Large Populations of Chemical Oscillators. Science 2009, 323, 614-617.

7. Toiya, M.; Vanag, V. K.; Epstein, I. R. Diffusively Coupled Chemical Oscillators in a Microfluidic Assembly. Angew. Chem. Int. Ed. 2008, 47, 7753-7755.

8. Ginn, B. T.; Steinbock, B.; Kahveci, M.; Steinbock, O. Microfluidic Systems for the Belousov-Zhabotinsky Reaction. J. Phys. Chem. A 2004, 108, 1325-1332.

9. Fukuda, H.; Tamari, N.; Morimura, H.; Kai, S. Entrainment in a Chemical Oscillator Chain with a Pacemaker. J. Phys. Chem. A 2005, 109, 11250-11254.

10. Tompkins, N.; Li, N.; Girabawe, C.; Heymann, M.; Ermentrout, G. B.; Epstein, I. R.; Fraden, S. Testing Turing's Theory of Morphogenesis in Chemical Cells. Proc. Natl. Acad. Sci U. S. A. 2014, 111, 4397-4402.

11. Vanag, V. K.; Epstein, I. R. Excitatory and Inhibitory Coupling in a One-Dimensional Array of Belousov-Zhabotinsky Micro-Oscillators: Theory. Phys. Rev. E 2011, 84, 066209. 
12. Torbensen, K.; Rossi, F.; Ristori, S.; Abou-Hassan, A. Chemical Communication and Dynamics of Droplet Emulsions in Networks of Belousov-Zhabotinsky Micro-Oscillators Produced by Microfluidics. Lab Chip 2017, 17, 1179-1189.

13. Elani, Y.; Solvas, X. C. I.; Edel, J. B.; Law, R. V.; Ces, O. Microfluidic Generation of Encapsulated Droplet Interface Bilayer Networks (Multisomes) and Their Use as Cell-Like Reactors. Chem. Commun. 2016, 52, 5961-5964.

14. Thutupalli, S.; Herminghaus, S.; Seemann, R. Bilayer Membranes in Micro-Fluidics: From Gel Emulsions to Soft Functional Devices. Soft Matt. 2011, 7, 1312-1320.

15. Guzowski, J.; Gizynski, K.; Gorecki, J.; Garstecki, P. Microfluidic Platform for Reproducible Self-Assembly of Chemically Communicating Droplet Networks with Predesigned Number and Type of the Communicating Compartments. Lab Chip 2016, 16, 764-772.

16. Rossi, F.; Zenati, A.; Ristori, S.; Noel, J-M.; Cabuil, V.; Kanoufi, F.; Abou-Hassan, A. Activatory Coupling among Oscillating Droplets Produced in Microfluidic Based Devices. Int. J. Unc. Comp. 2015, 11, 23-36.

17. Thutupalli, S.; Herminghaus, S. Tuning Active Emulsion Dynamics Via Surfactants and Topology. Europ. Phys. J. E 2013, 36, 1-10.

18. Nii, T.; Ishii, F. Properties of Various Phosphatidylcholines as Emulsifiers or Dispersing Agents in Microparticle Preparations for Drug Carriers. Colloid. Surface. B. 2004, 39, 57-63.

19. Baret, J.-C. Surfactants in Droplet-Based Microfluidics. Lab Chip 2012, 12, 422-433.

20. Torbensen, K.; Rossi, F.; Pantani, O. L.; Ristori, S.; Abou-Hassan, A. Interaction of the Belousov-Zhabotinsky Reaction with Phospholipid Engineered Membranes. J. Phys. Chem. B 2015, 119, 10224-10230.

21. Tomasi, R.; Noel, J.-M.; Zenati, A.; Ristori, S.; Rossi, F.; Cabuil, V.; Kanoufi, F.; Abou-Hassan, A. Chemical Communication between Liposomes Encapsulating a Chemical Oscillatory Reaction. Chem. Sci. 2014, 5, 1854-1859.

22. Li, N.; Delgado, J.; Gonzalez-Ochoa, H. O.; Epstein, I. R.; Fraden, S. Combined Excitatory and Inhibitory Coupling in a 1-D Array of Belousov-Zhabotinsky Droplets. Phys. Chem. Chem. Phys. 2014, 16, 10965-10978.

23. Stockmann, T. J.; Noël, J.-M.; Ristori, S.; Combellas, C.; Abou-Hassan, A.; Rossi, F.; Kanoufi, F. Scanning Electrochemical Microscopy of Belousov-Zhabotinsky Reaction: How Confined Oscillations Reveal Short Lived Radicals and Auto-Catalytic Species. Anal. Chem. 2015, 87, 9621-9630.

24. Gennis, R. B., Biomembranes; Springer Advanced Texts in Chemistry, 1989.

25. Zhang, J.; Unwin, P. R. Kinetics of Bromine Transfer across Langmuir Monolayers of Phosphatidylethanolamines at the Water/Air Interface. Phys. Chem. Chem. Phys. 2003, 5, 3979-3983. 26. Walter, A.; Gutknecht, J. Permeability of Small Nonelectrolytes through Lipid Bilayer Membranes. J.Membrane Biol. 1986, 90, 207-217.

27. Xiang, T. X.; Anderson, B. D. Permeability of Acetic Acid across Gel and Liquid-Crystalline Lipid Bilayers Conforms to Free-Surface-Area Theory. Biophys. J. 1997, 72, 223-237.

28. Benini, O.; Cervellati, R.; Fetto, P. Experimental and Mechanistic Study of the Bromomalonic Acid/Bromate Oscillating System Catalyzed by [Fe(Phen)3]2+. Int. J. Chem. Kinet. 1998, 30, 291-300.

29. Rossi, F.; Varsalona, R.; Liveri, M. L. T. New Features in the Dynamics of a Ferroin-Catalyzed Belousov-Zhabotinsky Reaction Induced by a Zwitterionic Surfactant. Chem. Phys. Lett. 2008, 463, 378-382.

30. Rossi, F.; Lombardo, R.; Sciascia, L.; Sbriziolo, C.; Liveri, M. L. T. Spatio-Temporal Perturbation of the Dynamics of the Ferroin Catalyzed Belousov-Zhabotinsky Reaction in a Batch Reactor Caused by Sodium Dodecyl Sulfate Micelles. J. Phys. Chem. B 2008, 112, 7244-7250.

31. Hoops, S.; Sahle, S.; Gauges, R.; Lee, C.; Pahle, J.; Simus, N.; Singhal, M.; Xu, L.; Mendes, P.; Kummer, U. Copasi-a Complex Pathway Simulator. Bioinformatics 2006, 22, 3067-3074. 


\section{TOC Graphic}

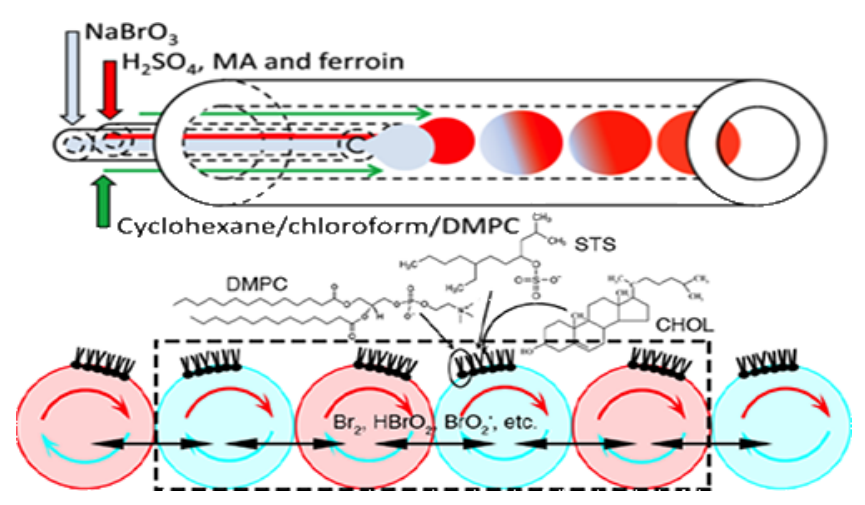

